\title{
Cold plasma in the nanotechnology of catalysts
}

\author{
Jacek Tyczkowski, Ryszard Kapica \\ Technical University of Lodz, Faculty of Process and Environmental Engineering, 90-924 Lodz, Wolczanska 213, Poland
}

In the paper the preparation of catalysts with the use of cold plasmas is discussed. A special attention is focused on nanocatalysts. In general, there are three main trends in this field: (1) plasma enhanced preparation of „classical” catalysts, (2) plasma sputtering of catalytically active compounds, especially metal and metal oxide nanoparticles, and (3) plasma-enhanced metal-organic chemical vapor deposition (PEMOCVD) of very thin metal and metal oxide films with specific nanostructure. It is shown that the cold plasma techniques are very effective methods for designing the nanocatalysts with distinct and tunable chemical activity, specificity and selectivity. Finally, our preliminary investigations concerning $\mathrm{CoO}_{\mathrm{x}}$ catalytic films fabricated by the PEMOCVD method are presented.

Keywords: catalysis; nanostructures; cold plasma; metal-organic chemical vapor deposition; cobalt oxides thin films.

\section{WHAT IS THE COLD PLASMA?}

Normally, we hardly come into contact with plasma in our daily life. The matter which is normally seen exists in the solid, liquid or gas phase. However, the conducting gas in a fluorescent tube or in a neon sign is in the plasma state. The lightning and the aurora appearing in the polar regions are plasmas in nature. All the stars, including the sun, are masses of high-temperature plasmas. We try to generate on the Earth in tokamaks and the machine- $\mathrm{Z}$ a similar plasma. The interstellar matter and nebulae are also formed by plasma, so it can be said that although the Earth is a place where plasmas appears only occasionally, the greater part of the universe is in the plasma state - the fourth state of the matter., 2

Only this short glance at the places where the plasma state exists shows that diametrically different types of plasma can be created (Fig. 1). Firstly, we can divide all gas plasmas into two groups: the low-temperature with partially ionized and the high-temperature with the fully ionized gas. The latter is used for nuclear fusion and is rather not interesting for chemists. In turn, among the low-temperature plasmas two basic kinds are distinguished: the thermal and the cold plasma. Although both kinds of the plasma are a partially ionized gas composed of ions, electrons and neutral species (among others, radicals), the cold plasma are characterized by the lack of thermal equilibrium between the electron temperature $\left(T_{\mathrm{e}}\right)$ and the gas temperature $\left(T_{g}\right)$. On the other hand, in the thermal plasma the energy distribution of electrons (characterized by $\mathrm{T}_{\mathrm{e}}$ ) and gas molecules (characterized by $\mathrm{T}_{\mathrm{g}}$ ) are nearly the same. This difference is of great importance to chemical processes that proceed in the plasma. In the case of the cold plasma, for which the most useful technique of its generation in laboratories and industry is the electrical glow discharge at low pressure, the electron temperature is in the range of $10^{4}-10^{5} \mathrm{~K}$ whereas the rest of the species are at the temperature close to the room temperature. Under such conditions we can perform chemical processes (e.g. chemical synthesis) at the room temperature using energetic electrons to cleavage covalent bonds in the gas molecules. By contrast, very high temperature of all the species in the thermal plasma considerably limits its application for the chemical synthesis and the surface modifications of thermal-degradable materials. ${ }^{3,4}$

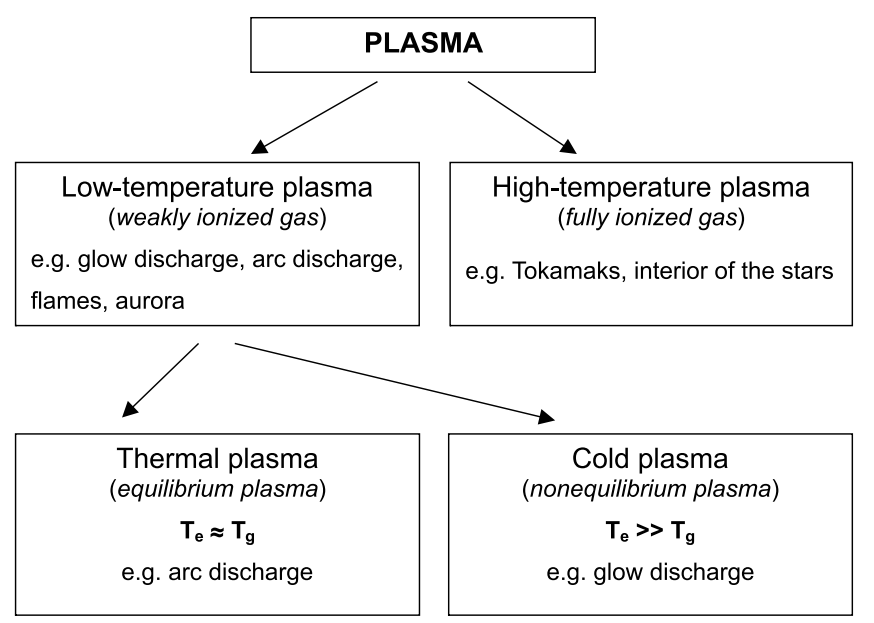

Figure 1. The classification of plasmas

Although the cold plasma constitutes only a small fraction of a wide domain of the fourth state of the matter, nevertheless for more than twenty years it has given rise to a development of a large number of modern technologies. The plasma deposition of very thin films of new materials as well as the plasma modification of conventional materials are the ones of the more significant among them. Recently, the cold plasma has turned out to be a very useful tool for nanotechnology, where $0-, 1-$, and 2dimensional nanoscale objects can be easily fabricated under full control. ${ }^{5}$ At the same time we have observed a growing interest in nanomaterials for catalysis. It has been found that such materials are often characterized by the non-typical catalytic properties giving higher activity, specificity and stability of the catalyst. ${ }^{6}$ So, it is not surprising that looking for new, more specific and active catalysts that could be deposited in the form of nanoscale objects on any support in practice, more and more often we turn to the cold plasma techniques. ${ }^{7,8}$

\section{COLD PLASMA METHODS IN CATALYST PREPARA- TION}

In general, there are three main trends in the catalyst preparation using cold plasma: (1) plasma enhanced preparation of „classical” catalysts, (2) plasma sputtering of catalytically active compounds, especially metal and metal oxide nanoparticles, and (3) plasma-enhanced metal-or- 
ganic chemical vapor deposition (PEMOCVD) of very thin metal and metal oxide films with specific nanostructure.

\section{Plasma enhänced preparation of „conventional” catalysts}

There are two techniques regarding plasma enhanced preparation of catalysts: plasma treatment during the catalyst formation and plasma modification of a catalyst that has been already conventionally formed. The first technique can be used to replace the thermal calcination of a catalyst as well as to modify the catalyst's structure. Due to the chemical treatment with the active plasma species the catalysts prepared in this way are usually very different from those calcined conventionally. For example, Zhang et al. ${ }^{9}$ reported plasma enhanced formation of a $\mathrm{Ni} / \alpha-\mathrm{Al}_{2} \mathrm{O}_{3}$ catalyst for methane conversion to syngas. First, the radio frequency (r.f.) argon plasma (generated at 13.56 MHz) was used for the decomposition of $\mathrm{Ni}\left(\mathrm{NO}_{3}\right)_{2}$ into $\mathrm{Ni}_{2} \mathrm{O}_{3}$. Then, the hydrogen r.f. plasma was applied for the reduction of the oxide film. The $\mathrm{Ni}_{2} \mathrm{O}_{3}$ film converted at the first to $\mathrm{NiO}$, and then to $\mathrm{Ni}$. The plasma prepared catalyst showed a better activity and stability, compared to the catalyst prepared conventionally. The total treatment time was less than $3 \mathrm{~h}$ (1.5 h for the argon plasma treatment and $65 \mathrm{~min}$ for the hydrogen plasma reduction) at the discharge tube temperature of $65^{\circ} \mathrm{C}$, while the conventional preparation of the catalyst needed $10 \mathrm{~h}$ of calcination at $900^{\circ} \mathrm{C}$ and $1 \mathrm{~h}$ of reduction at $600^{\circ} \mathrm{C}$.

Recently, an exciting comparison between the conventional $\mathrm{Pd} / \alpha-\mathrm{Al}_{2} \mathrm{O}_{3}$ catalyst for the selective hydrogenation of acetylene to ethylene and such a catalyst prepared by applying the plasma technique has been presented by Chen et al. ${ }^{10}$ Both procedures of the preparation are shown in Fig. 2. It has been found that the catalysts prepared by the plasma procedure exhibit a significant increase in activity and selectivity, compared with the conventional samples, especially at the lower reaction temperature. Typical results are given in Table 1, where a drastic difference between the plasma and the conventionally fabricated $\mathrm{Pd} / \alpha-\mathrm{Al}_{2} \mathrm{O}_{3}$ catalysts is evident. Moreover, it should be pointed out that the plasma processing is quick, clean and easy to be controlled.

The investigations performed by Liu et al. ${ }^{11}$ confirm that plasma treatment during the fabrication of the conventional catalyst is critical to the formation of its structure. They have shown that the glow discharge Ar plasma treatment evidently modifies the structure of palladium catalyst supported by a zeolite (Pd/HZSM-5). An enhanced dispersion of $\mathrm{PdO}$ and an increase in Brönsted and Lewis acidities, which leads to a remarkable improvement in the catalyst stability, have been observed. It has been also found that methane combustion (to carbon dioxide and water) over the plasma treated catalyst is close to $100 \%$ at $450^{\circ} \mathrm{C}$, but it is only ca. $50 \%$ at the same temperature over the catalyst without plasma treatment. Then, the investigations performed on a Mo-Fe/HZSM-5 catalyst, tested for the non-oxidative aromatization of methane,

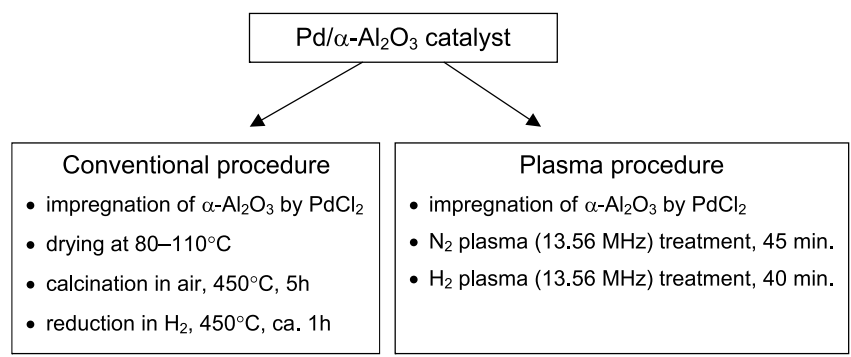

Figure 2. Two ways of preparing the $\mathrm{Pd} / \alpha-\mathrm{Al}_{2} \mathrm{O}_{3}$ catalyst. ${ }^{10}$

have shown that the Ar plasma treatment benefits the formation of the carbonaceous species associated with the active species of $\mathrm{MoC}_{\mathrm{X}}$ and disfavors coke formation that leads to the deactivation of the catalyst. ${ }^{\mathbf{1 2}}$

The crucial role of plasma treatment in the catalyst structure creation has been shown by Legrand et al. ${ }^{13}$ as well. They used a remote hydrogen microwave plasma $(2.45 \mathrm{GHz})$ for the preparation of gold-based metallic catalysts. Gold is introduced either to increase the dispersion of the more active metal, or to increase the turnover number, selectivity or stability. However, gold tends to sinter easily and the conventional reduction of gold performed in hydrogen at high temperature very often leads to large particles that are not active catalysts. The particles obtained by using the plasma are less than $5 \mathrm{~nm}$ in size, and are stable to thermal treatment.

The evident changes in the properties of a conventional catalyst can be also achieved by plasma treatment of its final commercial form. For example, Ar plasma treatment of the Ni catalyst used for partial oxidation of methane to syngas causes an increase in the catalytic activity and Ni dispersion. Moreover, the plasma treatment improves the catalytic stability by preventing the carbon deposition on the Ni catalyst. ${ }^{14}$ Similar changes in the catalytic properties have been also observed for the $\mathrm{Ni}$ catalyst and the Pt catalyst treated by He plasma. ${ }^{\mathbf{1 5}}$ The plasma treatment can be also used for making conventional catalysts in a unique form. For example, Gao et al. ${ }^{\mathbf{1 6}, 17}$ employed the $\mathrm{N}_{2}$ microwave plasma to fabricate a nano-sized Fe catalyst for carbon nanotube synthesis. A very thin Fe film was deposited on a Si substrate by the pulse laser technique and then it was treated by the plasma. Under the best optimum condition, the Fe catalyst in the form of nano ,islands" with the density of $1.9 \times 10^{15} \mathrm{~m}^{-2}$ and the diameter of about $15 \mathrm{~nm}$ were obtained. Carbon nanotubes (CNTs) synthesized on this catalyst were shown to have almost the same size and density as those of the nano ,islands".

The plasma technique has turned out to be very useful not only in the preparation process of conventional catalysts, but also for their regeneration. It has been found that the rate of reduction is several times higher for the plasmatreated deactivated catalysts than for the untreated ones. Furthermore, the activity of the regenerated catalysts is usually higher than that of the fresh catalyst. ${ }^{7}$

Table 1. The reaction results of two $\mathrm{Pd} / \alpha-\mathrm{Al}_{2} \mathrm{O}_{3}$ catalysts prepared by the conventional and the plasma procedure. ${ }^{10}$

\begin{tabular}{|l|c|c|c|c|c|}
\hline \multirow{2}{*}{ Sample } & \multirow{2}{*}{$\begin{array}{c}\mathrm{Pd} \text { content } \\
\text { (wt.\%) }\end{array}$} & \multicolumn{2}{|c|}{$\begin{array}{c}\text { Activity } \\
\mathrm{C}_{2} \mathrm{H}_{2} \text { conversion (\%) }\end{array}$} & \multicolumn{2}{c|}{ Selectivity } \\
\cline { 2 - 6 } & & $50^{\circ} \mathrm{C}$ & $9 \mathrm{H}_{4}$ formation (\%) & $90^{\circ} \mathrm{C}$ \\
\hline Conventional & 0.15 & 0.96 & 20.57 & $40^{\circ} \mathrm{C}$ & 7.22 \\
\hline Plasma & 0.15 & 100.00 & 100.00 & 71.27 & 50.08 \\
\hline
\end{tabular}




\section{Plasma sputtering of catalytic nanoparticles}

The theory and practice of heterogeneous catalysis have demonstrated that the activity of solid-phase catalysts is determined by their chemical and phase composition, crystal structure, and active specific surface. A close relation has been observed between the catalyst activity and the specific surface of the catalysts. In this regard, the ultrafine particle catalysts attract special attention because of their large specific surface and the less-perfect crystal lattice with a large number of vacancies. These induce a high catalytic activity. One of the most efficient methods for producing the ultrafine particles of the order of a few tens of nanometers with a highly developed specific surface and a high catalytic activity is the thermal plasma technique ${ }^{\mathbf{8}}$ (see Fig. 1). Recently, however, more and more attention has been focused on the cold plasma technique, and more specifically - on the plasma sputtering deposition. A schematic diagram of a typical set-up for sputtering deposition is sketched in Fig. 3. Positive ions that are produced in r.f. plasma generated in an inert gas, for example argon, bombard the target surface (supplied with the negative self-bias) and cause the sputtering of its material. The sputtered material condenses on the substrate that is located out of the plasma region. If we use some reactive gas (e.g. oxygen, nitrogen, methane) instead of argon, the target material takes part in chemical processes after sputtering and finally a new converted material is deposited. This is the so-called reactive plasma sputtering. ${ }^{18}$

Depending on the sputtering conditions we can obtain the deposit in various forms, also as separated or coalesced nanoparticles. It has been shown that $\mathrm{Pd}, \mathrm{Pt}, \mathrm{Rh}$, $\mathrm{Pt}_{\mathrm{X}} \mathrm{Rh}_{\mathrm{Y}},{ }^{19-22}$ as well as $\mathrm{Pt}_{\mathrm{X}} \mathrm{Ru}_{1-\mathrm{X}}, \mathrm{Pt}-\mathrm{RuO}_{\mathrm{X}}, \mathrm{Ni}_{\mathrm{X}} \mathrm{Zr}_{\mathrm{Y}}{ }^{23}$ can be deposited in such a catalytic active form. We can easily obtain nanoparticles of these materials as small as a few nanometers. Brault et al., ${ }^{22}$ for example, have recently studied plasma sputtering deposition of platinum into porous fuel cell electrodes. They have obtained platinum nano-clusters of $3.5 \mathrm{~nm}$, which penetrate the porous carbon electrode up to $2 \mu \mathrm{m}$ in depth. It should be also emphasized that although the electrode work is comparable with commercially available electrodes, it has a platinum density 4.5 times lower and hence can be considered to be significantly more effective.

\section{Plasma-enhanced metal-organic chemical vapor deposition (PEMOCVD)}

One of the very promising methods for producing catalytic structures is the plasma deposition of very thin films from metalorganic precursors supplied to the plasma reactor as a gaseous phase. This well-known method of thin film deposition, commonly called the plasma polymerization or speaking more precisely in this case - plasma enhanced metal-organic chemical vapor deposition (PEMOCVD), has already been used to fabricate a lot of thin-film materials for various practical applications. ${ }^{24}$ In the late eighties a possibility of the use of PEMOCVD for the preparation of catalytic films such as $\mathrm{Pd}, \mathrm{Rh}, \mathrm{Pt}$ was also mentioned, ${ }^{25-27}$ however, the direct involvement of this method in the field of catalysis has been rather modest so far and only just it has attracted closer attention. The interest in PEMOCVD is mainly provoked by the

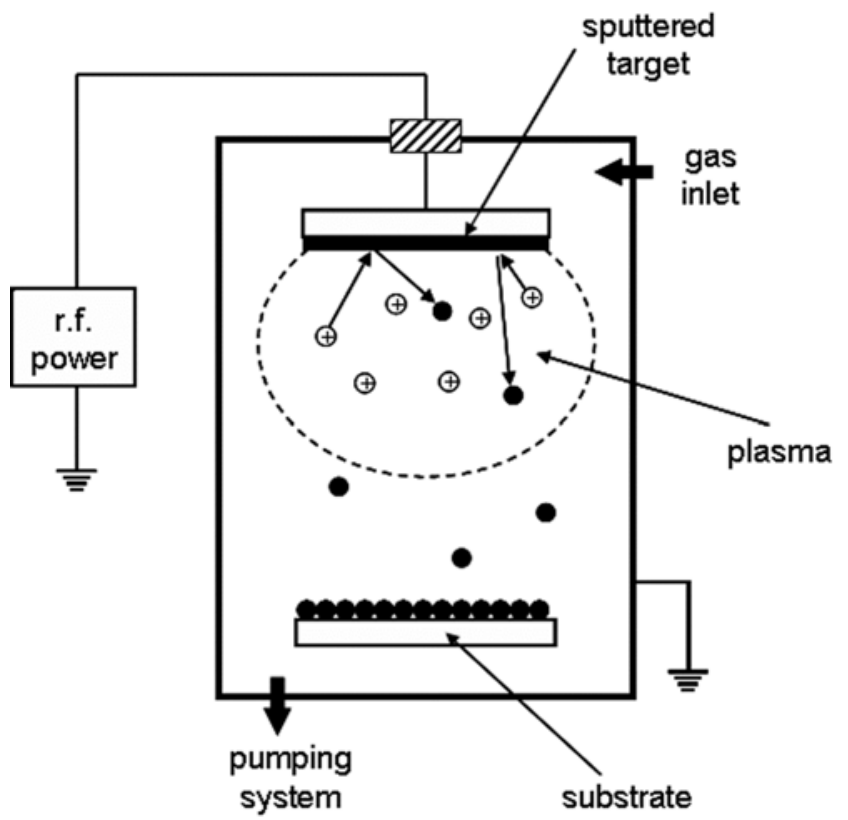

Figure 3. A schematic diagram of a typical set-up for sputtering deposition

search for new effective methods for preparing microchannel structures, in which a catalyst in the form of several-nanometer-clusters should be uniformly dispersed throughout the microstructure. Microchannel reactors have significant advantages over packed bed reactors, including faster heat and mass transfer which allow for the process miniaturization without the loss of the throughput. ${ }^{28}$ It is also important that the application of the cold plasma is especially useful for the preparation of supported nano-sized catalysts, because aggregations caused by thermal treatment might be avoided. In this way the particles of $\mathrm{CoO}_{\mathrm{X}}$ as small as 2-10 nm in diameter were deposited with success on the $\mathrm{TiO}_{2}$ support. ${ }^{29}$

There are two possible ways to start the decomposition process of metalorganic molecules in the plasma. The ligands of the evaporating precursor can be partly decomposed in the gas phase and the rest is deposited on the substrate surface or the precursor molecules are adsorbed on the surface without decomposition. Subsequently, their decomposition takes place during the plasma interaction with the substrate. In general, by controlling the plasma process parameters, the organic ligands of the precursor should be completely removed from the substrate surface. However, very often there is some amount of carbon in the deposit. To eliminate the carbon contamination, oxygen plasma treatment, ${ }^{\mathbf{2 9}}$ heated substrates, ${ }^{\mathbf{3 0}}$ as well as heat treatment after plasma deposition, ${ }^{\mathbf{2 8}}$ are practiced.

A few examples of metalorganic compounds used recently for the plasma deposition of catalytic materials are presented in Table 2. As you can see, the PEMOCVD method can be successfully applied for the preparation of various catalytic materials. Although the catalytic activity and selectivity of these materials in many cases is only just the matter under investigation, we have already learned that the results are very promising. For example, Karches et al. ${ }^{31}$ have shown in their exploratory investigations that plasma deposited thin films of $\mathrm{TiO}_{2}$ (with thickness of 7 $-120 \mathrm{~nm}$ ) reveal an efficiency of the photodecomposition of oxalic acid comparable with a commercial catalyst. Koyano et al., ${ }^{32}$ in turn, prepared cobalt oxide, using 
Table 2. The examples of metalorganic compounds used recently for the plasma deposition of catalytic materials

\begin{tabular}{|c|c|c|c|c|}
\hline Metalorganic compound & Denotation & Type of plasma & $\begin{array}{l}\text { Deposited } \\
\text { material }\end{array}$ & References \\
\hline cobalt(III)acetyloacetonate & $\mathrm{Co}(\mathrm{acac})_{3}$ & $\begin{array}{c}\text { mw plasma } \\
(2.46 \\
\mathrm{GHz})\end{array}$ & $\mathrm{CoO}_{x}$ & [29] \\
\hline platinum(II)acetyloacetonate & $\mathrm{Pt}(\mathrm{acac})_{2}$ & 13.56 MHz r.f. external coil & $\mathrm{Pt}$ & [28] \\
\hline $\begin{array}{l}\text { molybdenum pentacarbonyl- } \\
\text { 1-methylbutylisonitrile }\end{array}$ & $\mathrm{C}_{5} \mathrm{H}_{11} \mathrm{NCMo}(\mathrm{CO})_{5}$ & $\begin{array}{l}\mathrm{r}, \mathrm{f}, 13.56 \mathrm{MHz} \\
\text { remote plasma }\end{array}$ & $\mathrm{MoO}_{3}$ & {$[30]$} \\
\hline titanium tetra-t-butoxide & $\mathrm{Ti}(\mathrm{O} t \mathrm{Bu})_{4}$ & $\begin{array}{c}\text { r.f. } 13.56 \mathrm{MHz} \text { external } \\
\text { capacitor } \\
\text { or } \mathrm{mw} 2.46 \mathrm{GHz}\end{array}$ & $\mathrm{TiO}_{2}$ & {$[31]$} \\
\hline $\begin{array}{l}\text { platinum(II)acetyloacetonate } \\
\text { zirconium(IV)acetyloacetonate }\end{array}$ & $\begin{array}{l}\mathrm{Pt}(\mathrm{acac})_{2} \\
\mathrm{Zr}(\mathrm{acac})_{4}\end{array}$ & r.f. $13.56 \mathrm{MHz}$ external coil & $\begin{array}{l}\text { Pt-loaded } \\
\text { zirconia }\end{array}$ & [38] \\
\hline cyclopentadienyldicarbonylcobalt(I) & $\mathrm{CpCo}(\mathrm{CO})_{2}$ & $\begin{array}{c}\text { r.f. } 13.56 \mathrm{MHz} \\
\text { internal electrodes }\end{array}$ & $\mathrm{CoO}_{x}$ & $\begin{array}{l}\text { our results } \\
\text { (see the next } \\
\text { section) }\end{array}$ \\
\hline
\end{tabular}

$\mathrm{Co}\left(\mathrm{OCOCH}_{3}\right)_{2}$ and oxygen plasma, with higher dispersion and higher catalytic activity in the oxidation of $\mathrm{CO}$ and propane than those typical of the $\mathrm{CoO}_{\mathrm{X}}$ catalysts prepared by wet-chemical methods.

Consequently, the advantages to be gained from adopting the PEMOCVD method to catalyst preparation are evident. Beside the high activity we can also mention a reduced number of processing steps, substrates and energy saving and environmental benefits due to minimization of waste. It is no wonder that further extensive investigations in this field are declared. ${ }^{28,29}$

\section{COBALT OXIDE CATALYST DEPOSITED BY PEMOCVD}

Recently, we have undertaken an attempt at employing the PEMOCVD method to produce thin $\mathrm{CoO}_{\mathrm{X}}$ films that could play the role of the catalytic surface of a structured catalyst for gaseous hydrocarbons combustion. ${ }^{33}$ The preliminary results of the investigations proved to be promising and they are briefly presented below.

\section{Deposition of the films}

The cobalt-based films ( 25 - $750 \mathrm{~nm}$ thick $)$, macroscopically homogeneous, were deposited in a parallel plate r.f. reactor $(13.56 \mathrm{MHz})$ using the total pressure of $45-$ $75 \mathrm{~Pa}$ and the glow discharge power of $80 \mathrm{~W}$. A schematic diagram of the reactor is presented in Fig. 4. It can be used both for the solid and liquid metalorganic precursors that are supplied to the reactor chamber with a carrier gas. In our case, cyclopentadienyldicarbonylcobalt(I) $\left(\mathrm{CpCo}(\mathrm{CO})_{2}\right)$, liquid under standard conditions, was used as the precursor. Three types of films were investigated: the first type was deposited from a mixture of $\mathrm{CpCo}(\mathrm{CO})_{2}$ and argon as the carrier gas, the second one - from $\mathrm{CpCo}(\mathrm{CO})_{2}$ and oxygen, and the third type was produced by pure oxygen plasma treatment of the first type films fabricated previously. All the films were deposited at ambient temperature on glass plates with the evaporated thick Au layer. The thickness of the films was determined by ellipsometric measurements.

\section{Structure of the films}

The preliminary investigations of the chemical structure of the films were performed by Raman spectroscopy.
In Fig. 5A, the representative Raman spectra for the first type of the films (Ar plasma; the film thickness approx. $750 \mathrm{~nm})$ and the second one $\left(\mathrm{O}_{2}\right.$ plasma; the film thickness approx. $50 \mathrm{~nm}$ ) are presented. Two evident regions of bands in the „Ar plasma" spectrum can be distinguished: the region between 150 and $900 \mathrm{~cm}^{-1}$ characteristic of cobalt oxide structures, on a larger scale shown in Fig. 5B, and the region of bands at $1200-1800 \mathrm{~cm}^{-1}$ assigned to carbon structures. The five bands shown in the former region most probably originate from $\mathrm{Co}_{3} \mathrm{O}_{4}$ (spinel) nanoclusters, ${ }^{34}$ just the structure that has been found to be a very active component for hydrocarbons oxidation and combustion. ${ }^{35,36}$ On the other hand, two bands in the carbon region correspond to the typical graphite $G$ line centered at around $1580 \mathrm{~cm}^{-1}$ and the so-called disordered graphite $D$ line centered around $1350 \mathrm{~cm}^{-1}$. It is widely recognized that the former line originates from lattice vibrations in the plane of the graphite-like rings whereas the latter line results from the disorder-allowed zone-edge mode of graphite clusters. It is suggested, however, that these lines can be also associated with the isolated benzene or condensed benzene rings. Moreover, the $G$ line may even be formed by the olefinic $s p^{2}$ bonds alone. ${ }^{37}$

Without going into details concerning the molecular structure of the carbon component, it is evident that there is such a component in the films deposited with argon. On

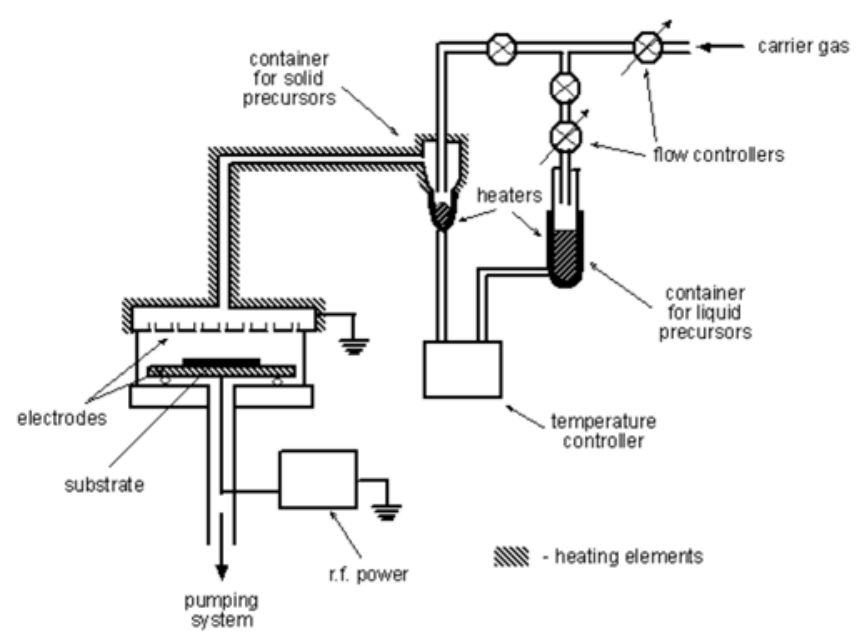

Figure 4. A schematic diagram of our r.f. reactor for the cobalt-based film deposition 

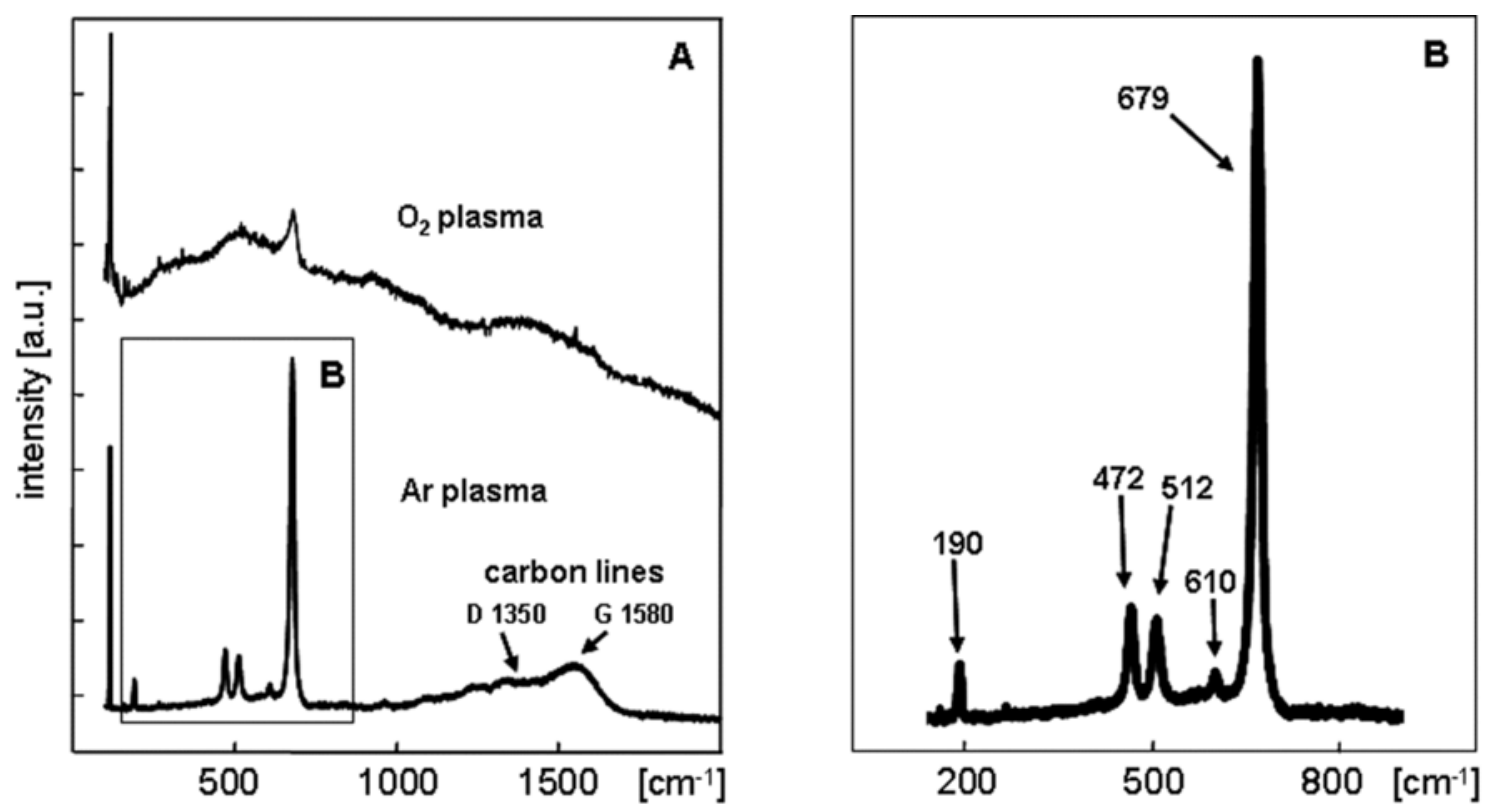

Figure 5. The Raman spectra for the films deposited from a mixture of $\mathrm{CpCo}(\mathrm{CO})_{2}$ and argon $\left(\mathrm{Ar}\right.$ plasma), and $\mathrm{CpCo}(\mathrm{CO})_{2}$ and oxygen $\left(\mathrm{O}_{2}\right.$ plasma): (A) - full spectra; (B) - the region of cobalt oxide structures from the Ar plasma spectrum on a larger scale

the contrary, the Raman spectrum for the film fabricated in the presence of oxygen (Fig. $5 \mathrm{~A}, \mathrm{O}_{2}$ plasma spectrum) does not reveal any carbon bands, which can be indicative of the absence of carbon structures in such a film. Unfortunately, the grow rate of the films is more than ten times lower than that for the films deposited with argon, so Raman spectroscopy measurements become much more difficult in this case. Nonetheless we can recognize in the spectrum the main characteristic band of $\mathrm{Co}_{3} \mathrm{O}_{4}\left(679 \mathrm{~cm}^{-1}\right)$. In order to obtain the films with the cobalt spinel and without carbon we have undertaken an attempt to eliminate the carbon component from the films previously deposited with argon by their oxygen plasma treatment. As you can see in Fig. 6, such tests have been unsuccessful so far.

Although the results presented above form only the preliminary part of the whole project concerning the structured catalysts, it shows that the plasma deposition from metalorganic precursors (PEMOCVD) is a very promising method to fabricate thin films containing $\mathrm{Co}_{3} \mathrm{O}_{4}$ nanoclusters. Indeed, only a superficial glance at the full widths at half maximum (FWHM) of our Raman bands for $\mathrm{Co}_{3} \mathrm{O}_{4}$ indicates a nanocrystal structure of this component. ${ }^{34}$ Investigations of the deposition process optimization as well as more detailed characterization of the film structure will be continued.

\section{CONCLUSIONS}

Plasma technology is an established key technology in microelectronic fabrication and in modern surface treatment. New applications of cold plasma to catalyst preparations have emerged as a promising future approach. There are three main trends in this field. Firstly, we can use cold plasma to improve the preparation of „classical” catalysts, secondly this plasma can be employed to prepare nano-sized particles of catalytic materials by sputtering, and last but not least, a new class of catalysts in the form of very thin films with specific nanostructure can be deposited by plasma polymerization of metalorganic pre- cursors (PEMOCVD). Very recently, the last method has been utilized by us to fabricate thin cobalt-based films with potentially catalytic properties. We have found that the films contain $\mathrm{Co}_{3} \mathrm{O}_{4}$ (spinel), most probably in the form of nanoclusters, thus in the form that has been recognized as a very active catalyst. Further investigations of these films are intensively carried out.

Tailoring of a supported catalyst remains a challenge especially when the structure of the catalytic material as well as the support is considered. The objective is to obtain the structurally well-defined catalysts with nanoparticles of a known structure, which are bound to the support in a controlled manner. It seems that especially the PEMOCVD technique is a very effective method for achieving supported nanoparticles of the catalytic active materials by the reaction between the functional groups at the support surface and a suitable metalorganic precursor.

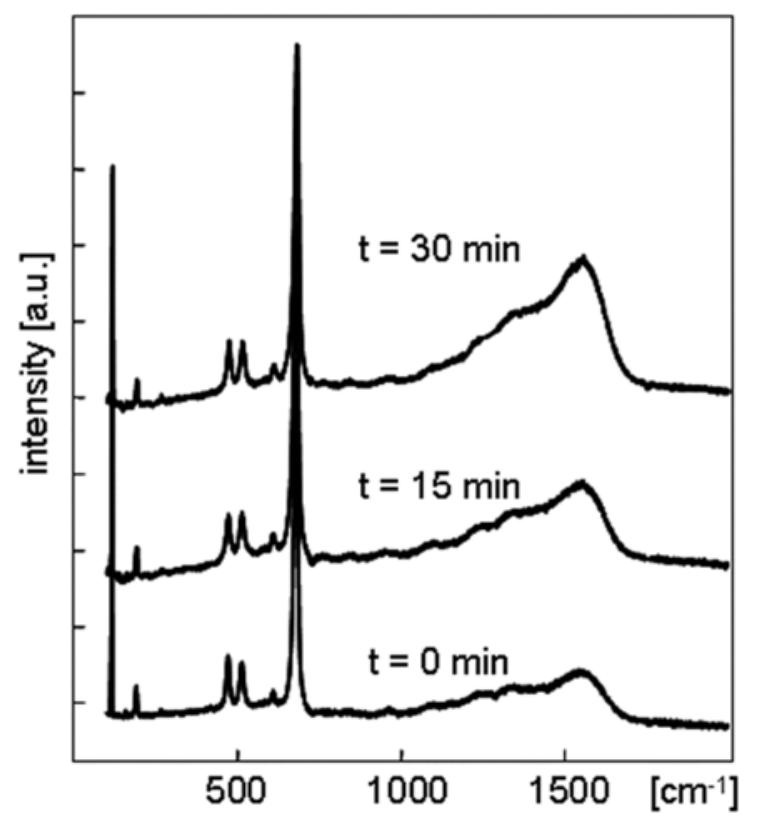

Figure 6. The Raman spectra for the films deposited from a mixture of $\mathrm{CpCo}(\mathrm{CO})_{2}$ and argon and then treated by oxygen plasma at different times 
The results obtained to date show that besides the high activity of the fabricated catalysts the PEMOCVD technique allows us to reduce the substrates and energy requirements as well as the environmental pollution in contrast with the conventional preparation methods, e.g. by wet impregnation. It should be also emphasized that in the case of structured catalysts, where extremely thin layers of catalytic active material is required, the conventional methods fail and the PEMOCVD technique opens new possibilities.

\section{Acknowledgment}

The study is based on the presentation during Third Microsymposium Molecular Engineering of Catalysts, Gliwice, 2005. This work has been performed partially in the framework of the KBN project code 3 T09C 04627. The authors are very grateful to Dr. M. Kozanecki for Raman spectroscopy measurements.

\section{LITERATURE CITED}

(1) Hollahan J. R., Bell A. T.: Techniques and Applications of Plasma Chemistry, Wiley, New York, 1974.

(2) Burch J. L., et al., (Eds.), Plasma Physics of the Local Cosmos, The National Academies Press, Washington, D.C., 2004.

(3) Konuma M.: Film Deposition by Plasma Techniques, Springer, Berlin, 1992.

(4) Grill A.: Cold Plasma in Materials Fabrication, IEEE Press, New York, 1994.

(5) Bhushan B.: (Ed.), Handbook of Nanotechnology, Springer, Berlin, 2004.

(6) Heiz U., Landman U.: (Eds.), Nanocatalysis, Springer, Berlin, 2006.

(7) Kizling M. B., Jaras S.G.: A review of the use of plasma techniques in catalyst preparation and catalytic reactions, Appl. Cat. A: General, 1996, 147, 1.

(8) Liu C. -J., Vissokov G. P., Jang B. W. -L.: Catalyst preparation using plasma technologies, Catal. Today, 2002, $72,173$.

(9) Zhang Y., Chu W., Cao W., Luo C., Wen X., Zhou K.: A plasma-activated $\mathrm{Ni} / \alpha-\mathrm{Al}_{2} \mathrm{O}_{3}$ catalyst for the conversion of $\mathrm{CH}_{4}$ to syngas, Plasma Chem. Plasma Processing, 2000, 20, 137.

(10) Chen M. H., Chu W., Dai X. Y., Zhang X. W.: New palladium catalysts prepared by glow discharge plasma for the selective hydrogenation of acetylene, Catal. Today, 2004, 89, 201.

(11) Liu C. -J., Yu K., Zhang Y. -P., Zhua X., Hea F., Eliasson B.: Characterization of plasma treated Pd/HZSM5 catalyst for methane combustion, Appl. Cat. B: Environmental, 2004, 47, 95 .

(12) Zhu X., Yu K., Li J., Zhang Y. -P., Xia Q., Liu C. $\mathrm{J}$.: Thermogravimetric analysis of coke formation on plasmatreated Mo-Fe/HZSM-5 catalyst during nonoxidative aromatization of methane, React. Kinet.Catal. Lett., 2006, 87, 93.

(13) Legrand J. -C., Diamy A. -M., Riahi G., Randriamanantenasoa Z., Polisset-Thfoin M., Fraissard J., Application of a dihydrogen afterglow to the preparation of zeolite-supported metallic nanoparticles, Catal. Today, 2004, 89, 177.

(14) Li Z. -H., Tian S. -X., Wang H. -T., Tian H. -B.: Plasma treatment of $\mathrm{Ni}$ catalyst via a corona discharge, J. Molec. Catal. A: Chemical, 2004, 211, 149.

(15) Zhu Y. -R., Li Z. -H., Zhou Y. -H., Lv J., Wang H. -T.: Plasma treatment of $\mathrm{Ni}$ and Pt catalysts for partial oxidation of methane, React. Kinet.Catal. Lett., 2006, 87, 33.
(16) Gao J. S., Umeda K., Uchino K., Nakashima H., Muraoka K.: Control of sizes and densities of nano catalysts for nanotube synthesis by plasma breaking method, Mater. Sci. Eng. B, 2004, 107, 113.

(17) Gao J. S., Umeda K., Uchino K., Nakashima H., Muraoka K.: Plasma breaking of thin films into nano-sized catalysts for carbon nanotube synthesis, Mater. Sci. Eng. A, 2003, 352, 308.

(18) Rossnagel S. M., Cuomo J. J., Westwood W. D.: (Ed.), Handbook of Plasma Processing Technology; Fundamentals, Etching, Deposition, and Surface Interactions, Noyes Publ., Park Ridge, New Jersey, USA, 1990.

(19) Thomann A. L., Rozenbaum J. P., Brault P., Andreazza C., Andreazza P., Rousseau B., Estrade-Szwarckopf H., Berthet A., Bertolini J. C., Aires F. J. C. S., Monnet F., Mirodatos C., Charles C., Boswell R.: Plasma synthesis of catalytic thin films, Pure Appl. Chem., 2002, 74, 471.

(20) Thomann A. L., Rozenbaum J. P., Brault P., Andreazza-Vignolle C., Andreazza P.: Pd nanoclusters grown by plasma sputtering deposition on amorphous substrates, Appl. Surf. Sci., 2000, 158, 172.

(21) Berthet A., Thomann A. L., Aires F. J. C. S., Brun M., Deranlot C., Bertolini J. C., Rozenbaum J. P., Brault P., Andreazza P.: Comparison of $\mathrm{Pd} /($ bulk $\mathrm{SiC}$ ) catalysts prepared by atomic beam deposition and plasma sputtering deposition: characterization and catalytic properties, J. Catal., 2000, 190, 49.

(22) Brault P., Caillard A., Thomann A. L., Mathias J., Charles C., Boswell R. W., Escribano S., Durand J., Sauvage T.: Plasma sputtering deposition of platinum into porous fuel cell electrodes, J. Phys. D: Appl. Phys., 2004, 37, 3419.

(23) Narayanan S. R.: Development of advanced catalysts for direct methanol fuel cells, in Chalk, S.G. (Ed.), Progress Report for Hydrogen, Fuel Cells, and Infrastructure Technologies Program, U.S. Department of Energy, Washington, D.C., 2002.

(24) Tyczkowski J.: Electrical and optical properties of plasma polymers, in Biederman, H. (Ed.), Plasma Polymer Films, Imperial College Press, London, 2004.

(25) Feurer E., Suhr H.: Thin palladium films prepared by metal-organic plasma-enhanced chemical vapour deposition, Thin Solid Films, 1988, 157, 81.

(26) Etspüler A., Suhr H.: Deposition of thin rhodium films by plasma-enhanced chemical vapor deposition, Appl. Phys. A, 1989, 48, 373.

(27) Feurer E., Kraus S., Suhr H.: Plasma chemical vapor deposition of thin platinum films, J. Vac. Sci. Technol. A, 1989, 7, 2799.

(28) Dhar R., Pedrow P. D., Liddell K. C., Ming Q., Moeller T. M., Osman M. A.: Plasma-enhanced metal-organic chemical vapor deposition (PEMOCVD) of catalytic coatings for fuel cell reformers, IEEE Trans. Plasma Sci., 2005, 33, 138 .

(29) Dittmar A., Kosslick H., Müller J. P., Pohl M. M.: Characterization of cobalt oxide supported on titania prepared by microwave plasma enhanced chemical vapor deposition, Surf. Coat. Technol., 2004, 182, 35.

(30) Hamelmann F., Brechling A., Aschentrup A., Heinzmann U., Jutzi P., Sandrock J., Siemeling U., Ivanova T., Szekeres A., Gesheva K.: Thin molybdenum oxide films produced by molybdenum pentacarbonyl 1methylbutylisonitrile with plasma-assisted chemical vapor deposition, Thin Solid Films, 2004, 446, 167.

(31) Karches M., Morstein M., Rohr P. R. v., Pozzo R. L., Giombi J. L., Baltanás M. A.: Plasma-CVD-coated glass beads as photocatalyst for water decontamination, Catal. Today, 2002, 72, 267.

(32) Koyano G., Watanabe H., Okuhara T., Misono M.: Structure and catalysis of cobalt oxide overlayers prepared 
on zirconia by low-temperature-plasma oxidation, J. Chem.

Soc., Faraday Trans., 1996, 92, 3425.

(33) Kołodziej A., Łojewska J., Tyczkowski J., Kapica R., Żak J.: Nanostructured oxide catalysts for VOC combustion on microstructured catalytic reactor, in preparation to Catal. Today.

(34) Hadjiev V. G., Iliev M. N., Vergilov I. V.: The Raman spectra of $\mathrm{Co}_{3} \mathrm{O}_{4}$, J. Phys. C, 1988, 21, L199.

(35) Xiao T. -C., Ji S. -F., Wang H. -T., Coleman K. S., Green M. L. H.: Methane combustion over supported cobalt catalysts, J. Molec. Catal. A: Chemical, 2001, 175, 111.

(36) Zwinkels M. M., Jaras S. G., Menon P. G., Griffin T. A.: Catalytic materials for high-temperature combustion, Catal. Rev. Sci. Eng., 1993, 35, 319.

(37) Kazimierski P., Tyczkowski J., Hatanaka Y., Aoki T.: Transition from amorphous semiconductor to amorphous insulator in hydrogenated carbon-germanium films investigated by Raman spectroscopy, Chem. Mater., 2002, 14, 4694.

(38) Pedrow P. D., Dhar R., Moeller T. M., Ming Q., Liddell K. C., Osman M. A.: Synthesis of platinum-loaded zirconia on Fecralloy $^{\mathrm{R}}$ using composite plasma-polymerization films, $31^{\text {st }}$ IEEE International Conference on Plasma Science, Baltimore (USA), IEEE, Piscataway, NJ, USA, 2004, p.171. 